\title{
LETTERS
}

\section{Serum prolactin stress values in patients with systemic lupus erythematosus}

\author{
C Dostál, L Moszkorzová, L Musilová, Z Lacinová, J Marek, J Zvárová
}

Ann Rheum Dis 2003;62:487-488

O ver the past decade we have seen a gradual increase in reports giving more support to the hypothesis that mildly or moderately increased values of serum prolactin have a role in the pathogenesis and clinical activity of systemic lupus erythematosus (SLE). Jara et al summed up this information in an article published in a special edition of the international journal Lupus. " "Idiopathic hyperprolactinaemia" (hyperprolactin) has been confirmed under a variety of conditions by several authors, including us, ${ }^{2}$ in $20-30 \%$ of patients with SLE investigated; nevertheless, opinion continues to vary about its connection with greatly increased clinical activity of the disease. ${ }^{34}$

Prolactin is a hormone with a very wide range of action, and its effect on the immune response has been proved in both animal experiments ${ }^{5}$ and in humans. ${ }^{6}$ It is also one of the stress hormones, and the physiological 24 hour curve of its serum concentrations is similar to that of the growth hormone, a near relation, but not to those of the hormones along the line connecting the hypothalamus-pituitaryadrenocortex.

In our first experiments designed to reproduce the study of hyperprolactin in patients with SLE or even rheumatoid arthritis (RA), we took account of the fact, emphasised by endocrinologists, that prolactin as a stress hormone is released in repeated pulses rather than continually; this is true at least, for the prolactin of pituitary origin, though not prolactin secreted in lymphoid paracrine tissue. ${ }^{7}$ The secretion of prolactin in the adenohypophysis is controlled indirectly by suppressing the inhibitory factor, which is synthesised and released in the hypothalamus and which is identical to dopamine. ${ }^{8}$

Stress, whether mental or physical, acts on prolactin secretion in different ways so that its serum levels rise not only in response to stress such as surgery in general anaesthesia but also after vigorous exercise and accidents, particularly after thoracic wall injury. ${ }^{9}$ For that reason, in compliance with recommendations from endocrinologists, ${ }^{8}{ }^{10}$ we measured each time a number of successively taken samples. The samples were taken 2-3 hours after awakening, and in women of child bearing age 10-14 days after menses. The subjects under investigation spent the first 30 minutes relaxing physically and mentally; then a cannula was introduced into the cubital pit vein, and the first sample of blood taken after another 30 minutes, followed by two further samples each at 30 minute intervals. Intervals of 30 minutes were chosen because the biological half life of prolactin is 20-30 minutes.

Serum samples were taken from 130 subjects-that is, a total of 390 samples. These included 79 patients $(73$ women, six men) with a definite diagnosis of SLE. The degree of activity rated by the SLE Disease Activity Index ( SLEDAI) score and specific organ involvement of the patient varied. Sixty two $(78 \%)$ patients were evaluated as active-that is, the SLEDAI score was $\geqslant 4$ (mean (SD) $11.79(10.4))$. Seventeen $(22 \%)$ patients were found to have inactive disease, with a SLEDAI score $<4$ (mean (SD) $1.06(0.99)$ ). The observed raised serum concentrations of prolactin did not correlate with the SLEDAI

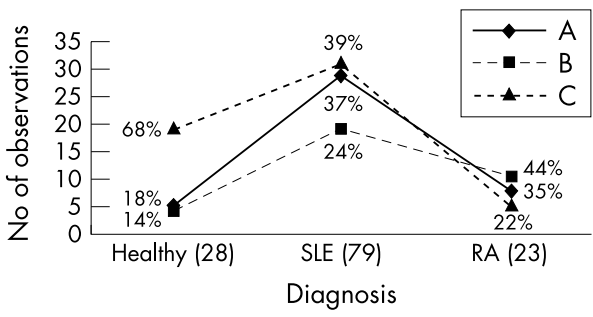

Figure 1 Association of raised prolactin with diagnosis (number of observations). Results are shown for the three groups investigated: healthy controls, patients with SLE, and RA. (A) Percentage of subjects with increased serum prolactin levels in all three blood samples; only these subjects meet the condition of increased serum prolactin and, consequently, the presence of "idiopathic hyperprolactinaemia". (B) Percentage of subjects with increased serum prolactin levels found in only one or two blood samples. An increase in only the first or in the first and second samples is taken as a sign of transitory reaction to stress caused by introducing a canula into the vein. (C) Percentage of subjects with normal serum prolactin levels found in all three blood samples; The between-group difference in the distribution of hyperprolactinaemia between the patients with SLE and RA and healthy controls is highly significant $(p<0.009)$

score activity (fig 1). Next, 23 patients (that is, 69 serum samples) with RA were investigated, who were also in different stages and activity of the disease. Twenty eight healthy subjects (that is, 84 serum samples), matched for age and sex with the SLE group, were investigated as controls. All patients and healthy controls receiving drugs known to influence prolactin secretion were excluded from the investigation.

The serum concentrations of prolactin were measured in duplicate by immunoradiometric assay (Immunotech, Prague). Prolactin levels gradually declined in successive serum samples (table 1). The differences in prolactin levels between samples 1 and 3 were highly significant for patients with SLE and RA. The statistical significance of this difference (between samples 1 and 3) was tested using the Wilcoxon matched pairs test in patients with SLE and RA, and healthy controls. The presence of hyperprolactin was rated as mild (200-350 mIU/l for men, 450-600 mIU/l for women), moderate (350-750 mIU/l for men, 600-1000 mIU/l for women), and high (>750 for men, $>1000$ for women). Serum hyperprolactin was found in 32/79 (41\%) patients with SLE, of whom 20 $(63 \%)$ had the mild type, nine $(28 \%)$ the moderate, and three (9\%) the high level type. In RA, serum hyperprolactin was found in $11 / 28(39 \%)$ patients, of whom eight (73\%) had the mild type, three $(27 \%)$ the moderate form, and none had the high level type. In healthy controls, serum hyperprolactin was found in 5/28 (18\%) subjects-all with the mild form. These figures apply only when increased concentrations of serum hyperprolactin were found in all three samples. If increased serum prolactin is found in only one or two samples the findings may easily be misinterpreted as seen from figure 1 . Thus for the 28 healthy subjects investigated raised levels were 
Table 1 Serum prolactin values in patients with SLE, RA, and in healthy controls (in three successively taken samples)

\begin{tabular}{|c|c|c|c|c|c|c|c|}
\hline & \multirow{2}{*}{$\begin{array}{l}\text { Serum prolactin level } \\
(\mathrm{mlU} / \mathrm{l})\end{array}$} & \multirow{2}{*}{$\begin{array}{l}\text { No of } \\
\text { observations }\end{array}$} & \multicolumn{4}{|c|}{ Serum prolactin (mIU/l) } & \multirow{2}{*}{$\begin{array}{l}\text { Difference between } \\
1 \text { st and 3rd sample } \\
\text { (p value) }\end{array}$} \\
\hline & & & & 1st Sample & 2nd Sample & 3rd Sample & \\
\hline \multirow[t]{8}{*}{ SLE $(n=79)$} & Raised & 29 & Mean & 700.72 & 618.79 & 572.17 & $<0.001$ \\
\hline & Men 200-750 & & $\mathrm{SD}$ & 420.13 & 386.42 & 378.29 & \\
\hline & Women 450-1000 & & $95 \% \mathrm{Cl}$ & 540 to 860 & 471 to 765 & 428 to 716 & \\
\hline & & & $Q_{3}-Q_{1}$ & 442 & 350 & 268 & \\
\hline & Normal & 50 & Mean & 293.12 & 271.28 & 246.71 & $<0.001$ \\
\hline & & & SD & 144.39 & 124.08 & 108.62 & \\
\hline & & & $95 \% \mathrm{Cl}$ & 252 to 334 & 236 to 306 & 215 to 277 & \\
\hline & & & $Q_{3}-Q_{1}$ & 141 & 181 & 171 & \\
\hline \multirow[t]{8}{*}{$\mathrm{RA}(\mathrm{n}=23)$} & Raised & 8 & Mean & 516.13 & 417.00 & 370.75 & $0.08 \mathrm{NS}$ \\
\hline & Men 200-750 & & SD & 423.30 & 352.01 & 236.02 & \\
\hline & Women 450-1000 & & $95 \% \mathrm{Cl}$ & 162 to 870 & 122 to 711 & 173 to 568 & \\
\hline & & & $Q_{3}-Q_{1}$ & 132 & 155 & 179 & \\
\hline & Normal & 15 & Mean & 227.93 & 206.33 & 191.00 & $<0.007$ \\
\hline & & & SD & 134.96 & 131.27 & 109.05 & \\
\hline & & & $95 \% \mathrm{Cl}$ & 153 to 302 & 133 to 279 & 130 to 251 & \\
\hline & & & $Q_{3}-Q_{1}$ & 126 & 78 & 55 & \\
\hline \multirow[t]{8}{*}{ Healthy ( $n=28$ ) } & Raised & 5 & Mean & 315.80 & 280.80 & 266.60 & $0.22 \mathrm{NS}$ \\
\hline & Men 200-750 & & SD & 84.45 & 46.48 & 93.18 & \\
\hline & Women 450-1000 & & $95 \% \mathrm{Cl}$ & 210 to 420 & 223 to 338 & 150 to 382 & \\
\hline & & & $Q_{3}-Q_{1}$ & 152 & 79 & 16 & \\
\hline & Normal & 23 & Mean & 166.43 & 163.96 & 163.61 & $0.75 \mathrm{NS}$ \\
\hline & & & $\mathrm{SD}$ & 59.92 & 59.248 & 63.00 & \\
\hline & & & $95 \% \mathrm{Cl}$ & 141 to 191 & 138 to 189 & 136 to 190 & \\
\hline & & & $Q_{3}-Q_{1}$ & 93 & 92 & 83 & \\
\hline
\end{tabular}

found in all three serum samples in five (18\%); in one or two samples in four (14\%); and normal levels were found in 19 (68\%). Similarly, for the 79 patients with SLE raised levels were found in all three serum samples in $29(37 \%)$; in one or two samples in 19 (24\%); and normal levels were found in 31 (39\%). Finally, for the 23 patients with RA raised levels were found in all three serum samples in eight (35\%); in one or two samples in 10 (44\%); and normal levels were found in five $(22 \%)$. Using Pearson's $\chi^{2}$ test for contingency table, we determined significant difference $(\mathrm{p}<0.01)$ in the distribution of normal or raised serum prolactin levels when three blood samples were taken or when one or two samples only were taken, between patients with SLE/RA and healthy controls.

Our conclusions are partly in agreement with the hypothesis advanced by Jara et al. ${ }^{1}$ Firstly, the level of increased serum prolactin secreted from the pituitary gland is variable unless it is under the influence of a microadenoma, on the one hand, or unless the readings are of paracrine origin (lymphoid tissue), on the other. Secondly, the level of prolactin is highest in the first blood sample taken, declining in samples taken subsequently, which indicates a stressful situation at the time of taking the initial sample, though this is found only in patients with SLE or RA, not in healthy controls. The possible disregulation due to the presence of a systemic autoimmune disease requires further study.

\section{ACKNOWLEDGEMENT}

This study was supported by the Internal Grant Agency of Ministry of Health of the Czech Republic No NK 5370-3/99.

\section{Authors' affiliations}

C Dostál, L Moszkorzová, L Musilová, Institute of Rheumatology, Na Slupi 4, Prague 2, 12850 Czech Republic

Z Lacinová, J Marek, 3rd Medical Department, 1st Medical Faculty, Charles University, Prague 2, Czech Republic

J Zvárová, EuroMMISE Centre, Charles University and Ac Sciences, Prague 2, Czech Republic

Correspondence to: Professor C Dostál; dosł@revma.cz

Accepted 8 October 2002

\section{REFERENCES}

1 Jara LY, Vera-Lastra O, Misauda JM, Alcola M, Alseter-Nemegyli J. Prolactin in human systemic lupus erythematosus. Lupus 2001;10/special issue):748-56.

2 Dostál C, Marek J, Moszkorzová L, Lacinová Z, Musilová L. Prolactin in systemic lupus erythematosus [abstract]. Lupus 2001;10(suppl 1):S38.

3 Blanco-Favela F, Quintal-Alvarez G, Leanos-Miranda A. Association between prolactin and disease activity in systemic lupus erythematosus. Influence of statistical power. J Rheumatol 1999;26:55-9.

4 Alcal'a M, Basile L, Miranda JM, Velazquez F, Funetes M, Jara LY. Does hyperprolactinemia secondary to microadenoma induce autoimmune diseases? [abstract]. Arthritis Rheum 1997;40(suppl 9):S 267.

5 Reber PM. Prolactin and immunomodulation. Am J Med 1993;95:637-44.

6 Neidhart $M$. Prolactin in autoimmune diseases. Proc Soc Exp Biol Med 1998;217:408-19.

7 Gutiérrez MA, Molina JF, Jara XY. Prolactin and systemic lupus erythematosus: prolactin secretion by SLE lymphocytes and proliferation (autocrine) activity. Lupus 1995;4:348-52.

8 Kelly PA. Growth hormone and prolactin. In: Bautien EE, Kelly PA, eds. Hormones. New York: Hermann, 1990: 1190-250.

9 Noel GL, Suh HK, Stone JG, Frantz AG. Human prolactin and growth hormone release during surgery and other times of stress. J Clin hormone release during surgery and othe
Endocrinol Metab 1972;35:840-51.

10 Drury PL, Howlett TA. Endocrinology. In: Kumar P, Clark M, eds. Clinical medicine. Edinburgh: Saunders WB, 1999:895-958 


\title{
Cyclosporin treatment in psoriatic arthritis: a cause of severe leg pain
}

\author{
C A Lawson, A Fraser, D J Veale, P Emery
}

Ann Rheum Dis 2003;62:489

\section{CASE REPORT}

We describe a case of severe leg pain in a young woman receiving cyclosporin. She was referred to our department at the age of 18 with psoriatic arthritis that had started five years previously. Owing to intolerance of sulfasalazine she had been receiving cyclosporin $100 \mathrm{mg}$ twice a day $(3.3 \mathrm{mg} / \mathrm{kg})$ for the preceding seven months before review in combination with methotrexate. Two weeks after referral to our department she began to develop non-specific thigh pains, and the possibility of myalgia due to cyclosporin was suggested. Her dose was reduced but with no change in symptoms. At this point she was taking regular opioids in an attempt to ease her symptoms.

She was admitted for further assessment. On questioning, her leg pain consisted of a burning sensation radiating from her thighs to her ankles, and was intermittent every one to two days lasting several hours at a time. She found relief from lying flat and applying local heat, but only minimal benefit from analgesia such as co-codamol. She had difficulty walking when pain was present and her sleep was disturbed. Examination showed the only abnormalities to be psoriatic plaques, nail pitting, and onycholysis. In particular, examination of the neurological and arterial systems was normal. Initial investigations included urea, creatinine, and electrolytes, a full blood count, liver function tests, $\mathrm{C}$ reactive protein, plasma viscosity, rheumatoid factor, antinuclear antibodies, creatine kinase, thyroid function tests, glucose, calcium, vitamin B12, folate, serum electrophoresis, urinary porphyrins, nerve conduction studies, and electromyelography, all of which were normal. A measured cyclosporin level was at the lower limit of the therapeutic range.

Trials with analgesia showed that only morphine sulphate eased the severe episodes of pain. The possibility of her symptoms representing a "bone pain syndrome' secondary to cyclosporin was suggested, and her cyclosporin was stopped with continuation of methotrexate. At review two weeks later her pain had completely resolved, and had done so within 48 hours of stopping treatment. In view of this very dramatic response to cyclosporin withdrawal, the description of her symptoms, and the lack of abnormal examination and investigation findings, we felt that this represented "cyclosporin induced leg pain".

\section{DISCUSSION}

There are several reports of this syndrome in patients with a renal transplant who are taking cyclosporin. Among the first was in 1994, describing 15 patients with a renal transplant who presented with severe bone pain that resolved with calcium channel blockade. ${ }^{1}$ More recently, a case of leg pain in a patient with Crohn's disease receiving cyclosporin treatment was reported. ${ }^{2}$ The published reports describe the pain characteristically as a bilateral deep aching sensation of acute onset, and episodic lasting several hours at a time. Reports include pain in the knees, ankles, wrists, shoulders, and thighs. Patients often feel worse at night or when lying flat. ${ }^{13}$ Pain severity can be linked to higher cyclosporin levels, and reducing the dose may alleviate symptoms. Examination is normal and there are no consistent blood or radiological abnormalities. It has been noted that other side effects of cyclosporin such as hypertension are present in $75 \%$ of patients with this type of pain, compared with $34 \%$ of asymptomatic patients despite the same mean cyclosporin levels. ${ }^{4}$

Calcium channel blockade appears to be an effective treatment, with a prospective study showing that almost all patients gained complete relief with nifedipine. ${ }^{3}$ In our patient it was felt preferable to stop cyclosporin, as her psoriatic arthritis was well controlled and she was continuing to receive methotrexate. Non-steroidal anti-inflammatory drugs and weak opioids have consistently been found to be ineffective. ${ }^{4}$ Suggested pathophysiological mechanisms of pain include vasoconstriction of bone vasculature, and interosseous hypertension as seen in sickle cell crisis. ${ }^{15}$ Of note is that an acute bone pain syndrome has also been documented in patients with a renal transplant taking tacrolimus.

This syndrome is rare but well documented in patients with a transplant. Many rheumatologists are not aware of this uncommon side effect, and, if undetected, it can lead to the use of potent analgesia in an attempt to alleviate symptoms. Cyclosporin is widely used in rheumatological practice, and this is a potentially treatable side effect if the cause is recognised.

\section{Authors' affiliations}

C A Lawson, A Fraser, D J Veale, P Emery, Department of Rheumatology and Rehabilitation, 36 Clarendon Road, Leeds LS2 9NZ, UK

Correspondence to: $\operatorname{Dr}$ C A Lawson, Molecular Medicine Unit, Clinical Sciences Building, St James's University Hospital, Leeds LS9 7TF, UK; medc|@leeds.ac.uk

Accepted 26 August 2002

\section{REFERENCES}

1 Gauthier VJ, Barbosa LM. Bone pain in transplant recipients responsive to calcium channel blockers. Ann Intern Med 1994:121:863-5.

2 Isaacs K. Severe bone pain as an adverse effect of cyclosporin therapy for Crohn's disease. Inflamm Bowel Dis 1998;4:95-7.

3 Barbosa LM, Gauthier VJ, Davis CL. Bone pain that responds to calcium channel blockers. A retrospective and prospective study of transplant recipients. Transplantation 1995;59:541-4.

4 Lucas VP, Ponge TD, Plougastel-Lucas ML, Glemain P, Hourmant M, Soulillou JP. Musculoskeletal pain in renal-transplant recipients. N Engl J Med 1991;325:1449-50.

5 O'Neill EA, Sloan VS. A potential mechanism of cyclosporin-associated bone pain: comment on the radiologic vignette by Stone et al. Arthritis Rheum 1998;41:565-6.

6 Villaverde V, Cantalejo M, Balsa A, Mola E, Sanz A. Leg bone pain syndrome in a kidney transplant patient treated with tacrolimus (FK506). Ann Rheum Dis 1999;58:653-64. 


\title{
Anti-tumour necrosis factor treatment in a patient with anorexia nervosa and juvenile idiopathic arthritis
}

\author{
J Barber, T Sheeran, D Mulherin
}

Ann Rheum Dis 2003;62:490-491

T umour necrosis factor $\alpha(\mathrm{TNF} \alpha)$ is believed to have a pivotal role in the pathogenesis of many forms of inflammatory arthritis, and anti-TNF $\alpha$ therapies are now licensed and recommended for the treatment of refractory rheumatoid arthritis and juvenile idiopathic arthritis (JIA). ${ }^{12}$ An important role for TNF $\alpha$ in the pathophysiology of anorexia nervosa has also been postulated, although authors differ on the precise mechanisms underlying its role. ${ }^{3}$ Some authors have suggested that TNF $\alpha$ may be mediating a stress response, whereas others have proposed that raised levels of TNF $\alpha$ in these patients may be secondary to anorexia rather than a cause. ${ }^{45}$ Although the role of anti-TNF $\alpha$ therapies in the management of inflammatory arthritis is well recognised, we are not aware of experience with the use of anti-TNF $\alpha$ treatment in the management of anorexia nervosa. We describe the effect of such treatment prescribed to a woman with refractory JIA and anorexia nervosa.

\section{CASE REPORT}

A 28 year old woman with JIA had a disease activity score of 6.68 despite continuing treatment with weekly methotrexate, $10 \mathrm{mg}$ orally. ${ }^{6}$ She originally presented to rheumatology care at age 14 years with a nine year history of pain, swelling, and stiffness of the small joints of the hands, wrists, temporomandibular joints, and feet, leading to significant deformity and disability. At that time, her height $(151 \mathrm{~cm})$ was on the 50th centile and her weight $\left(30 \mathrm{~kg}\right.$ ) on the 3 rd centile. ${ }^{7}$ Family habitus was described as thin. Rheumatoid factor was positive, antinuclear antibody was negative, the $\mathrm{C}$ reactive protein was raised $(36 \mathrm{mg} / \mathrm{l})$, and an ophthalmological review was normal. Intensive physiotherapy and non-steroidal treatment were instituted.

Her arthritis remained well controlled over the next two years. She gained $5 \mathrm{~cm}$ in height but only $1.8 \mathrm{~kg}$ in weight, and was noted to eat very little but denied drug or laxative abuse or self induced vomiting. The psychiatric service diagnosed a somewhat unusual presentation of anorexia nervosa with eating phobia and a feeling of being unattractive but at the same time a desire to be heavier. Recent stresses at home and at college were noted, but no psychotic features were identified. She received family therapy and had a spell of inpatient care for anorexia over the subsequent 18 months. Her arthritis remained inactive and her jaw malocclusion was surgically corrected, with improvement in her appearance.

At age 22 years, her arthritis flared with prolonged morning stiffness, swelling, and increasing deformity of hands, wrists, elbows, and knees. Weekly oral methotrexate treatment was instituted, but her arthritis remained problematic and she required several intra-articular injections over the ensuing years. At age 24 years her weight was $33.8 \mathrm{~kg}$, and she was admitted again for treatment of her eating disorder, but with little increase in weight ensuing. At age 27 years her weight had fallen from a peak of $33.9 \mathrm{~kg}$ to $32 \mathrm{~kg}$, with evidence of active arthritis, increased articular deformity, and functional deterioration despite increased methotrexate treatment. At age 28 years, with evidence of active disease despite methotrexate treatment, and weighing $29 \mathrm{~kg}$, infliximab treatment was instituted. Within two weeks, her mood improved, as did her appetite, and improvement in her articular symptoms was also seen: five months after starting treatment, her weight had risen to $31.5 \mathrm{~kg}$, an $8 \%$ increase over her pretreatment weight.

\section{DISCUSSION}

Anorexia nervosa is a severe eating behaviour disorder, characterised by weight loss below $85 \%$ of the expected body weight, amenorrhoea, and a distorted body image with associated significant morbidity and mortality. ${ }^{8}$ It can be distinguished from the constitutional weight loss seen in inflammatory arthropathies by the associated behavioural and perceptual changes relating to food and body image. Clearly, other important causes of weight loss in these patients include occult infection and malignancy or simply the anorexia related to nauseating treatment. TNF $\alpha$ was originally described as "cachexin", and severe inflammatory arthritis is known to be associated with both cachexia and raised TNF $\alpha .{ }^{9}{ }^{10} \mathrm{TNF} \alpha$ has also been postulated to play an important part in the development of anorexia nervosa. ${ }^{3}$ Profound anorexia and pathological weight loss were certainly major features of this patient's disease. Although she satisfied criteria for a diagnosis of anorexia nervosa, it is clearly possible that some of her anorexia stemmed from her underlying inflammatory joint disease: it is impossible to separate these two processes. However, she exhibited abnormal eating behaviour even at times when her arthritis was clinically quiescent, suggesting that her arthropathy alone was not the exclusive cause of her arthritis. Her preliminary response to infliximab raises the intriguing possibility of a new treatment for the potentially life threatening disorder of anorexia nervosa. This clearly warrants further evaluation.

\section{Authors' affiliations \\ J Barber, T Sheeran, D Mulherin, Department of Rheumatology,} Cannock Chase Hospital, Brunswick Road, Cannock, WS 11 2XY, UK

Correspondence to: Dr D Mulherin;

diarmuid.mulherin@msgh-tr.wmids.nhs.uk

Accepted 7 October 2002

\section{REFERENCES}

O'Dell JR. Anticytokine therapy - a new era in the treatment of rheumatoid arthritis? N Engl J Med 1999:340:310-12.

2 Lovell DJ, Giannini EH, Reiff A, Cawkwell GD, Silvermann ED, Nocton $\mathrm{JJ}$, et al. Etanercept in children with polyarticular juvenile rheumatoid arthritis. N Engl J Med 2000;342:763-9.

3 Holden RJ, Pakula IS. The role of tumour necrosis factor-alpha in the pathogenesis of anorexia and bulimia nervosa, cancer cachexia and obesity. Med Hypotheses 1996;47:423-38.

4 Allende LM, Corell A, Manzanares J, Madruga D, Marcos A Lopez-Goyanes A, et al. Immunodeficiency associated with anorexia nervosa is secondary and improves after refeeding. Immunology 1998;94:543-51. 
5 Holden RJ, Pakula IS. Tumour necrosis factor-alpha: is there a continuum of liability between stress, anxiety states and anorexia nervosa? Med Hypotheses 1999;52:155-62

6 van der Heijde DMFM, van't Hof MA, van Reil PLCM, Theunisse LAM, Lubberts $E W$, van Leeuwen MA, et al. Judging disease activity in clinical practice in rheumatoid arthritis: first step in the development of a disease activity score. Ann Rheum Dis 1990;49:916-20

7 Tanner JM, Buckler JM. Revision and update of Tanner-Whitehouse clinical longitudinal charts for height and weight. Eur J Paediatr 1997; 156:248-9.
8 Lowe B, Zipfel S, Buchholz C, Dupont Y, Reas DL, Herzog W. Long-term outcome of anorexia nervosa in a prospective 21 -year follow-up study. Psychol Med 2001;31:881-90.

9 Beutler B, Greenwald D, Hulmes JD, Chang M, Pan YC, Mathison J, et al. Identity of tumour necrosis factor and the macrophage secreted factor cachectin. Nature 1985:316:552-4.

10 Roubenoff R, Roubenoff RA, Ward LM, Holland SM, Hellmann DB. Rheumatoid cachexia: depletion of lean body mass in rheumatoid arthritis. Possible association with tumour necrosis factor. J Rheumatol 1992; 19:1505-10.

\section{Transient joint effusion: a forgotten side effect of high dose corticosteroid treatment}

\section{F Schiavon}

P ulse therapy with high doses of corticosteroids, although generally well tolerated, is associated with a variety of side effects, sometimes life threatening but, more often, mild. Among these, joint manifestations are only rarely encountered. Patients sometimes feel transient arthralgias, but the development of synovial effusion is exceptionally reported.

We described the case of a woman with systemic lupus erythematosus (SLE) and nephritis who developed a transient bilateral knee synovial effusion during pulse therapy with a high dose of corticosteroids.

\section{CASE REPORT}

A 62 year old woman was admitted to our division because of SLE with nephritis. Eight months before the admission, in April 2000, she developed arthritis in the last four toes of the left foot. She was treated with non-steroidal antiinflammatory drugs, with complete remission. Serological findings showed a raised erythrocyte sedimentation rate (ESR) of $52 \mathrm{~mm} / \mathrm{lst} \mathrm{h}$, normal $\mathrm{C}$ reactive protein, and a decrease in total protein and albumin. Three months later laboratory features showed an increase in ESR $(62 \mathrm{~mm} / \mathrm{lst} \mathrm{h})$, fibrinogen $(4.4 \mathrm{~g} / \mathrm{l})$, proteinuria $(5 \mathrm{~g} / 24 \mathrm{~h})$, and haematuria ( $>5$ red blood cells (RBC)/high power field), with normal renal function and a decrease in total protein and albumin and the presence of antinuclear (ANA) and anti-Sm antibodies. Therefore she was admitted to our division where she had a kidney biopsy, which showed a mesangioproliferative glomerulonephritis (WHO class III). After four months of inadequate response to traditional treatment, she started monthly pulse corticosteroid therapy ( $1 \mathrm{~g}$ methylprednisolone for three days) before immunosuppressive drugs.

At admission we did not observe any arthritis. On the evening of the second day of pulse steroid therapy, after a short walk, she complained of pain and flexion discomfort to both knees, which a physical examination showed were swollen. Thus, an arthrocentesis was performed with aspiration of synovial fluid $(5 \mathrm{ml}$ from the right and $6 \mathrm{ml}$ from the left knee). Synovial fluid analysis showed a colourless fluid, with high viscosity and excellent mucin clot formation (fig 1). A leucocyte count disclosed only 1 mononucleate cell $/ \mathrm{mm}^{3}$ in the right knee synovial fluid and no cells in the left. No crystals were identified by light or compensated polarised microscopy. Inflammatory laboratory measurements carried out simultaneously were unchanged. Radiographs of the affected joints showed normal aspects. Effusion resolved with arthrocentesis and did not recur during admission to hospital.

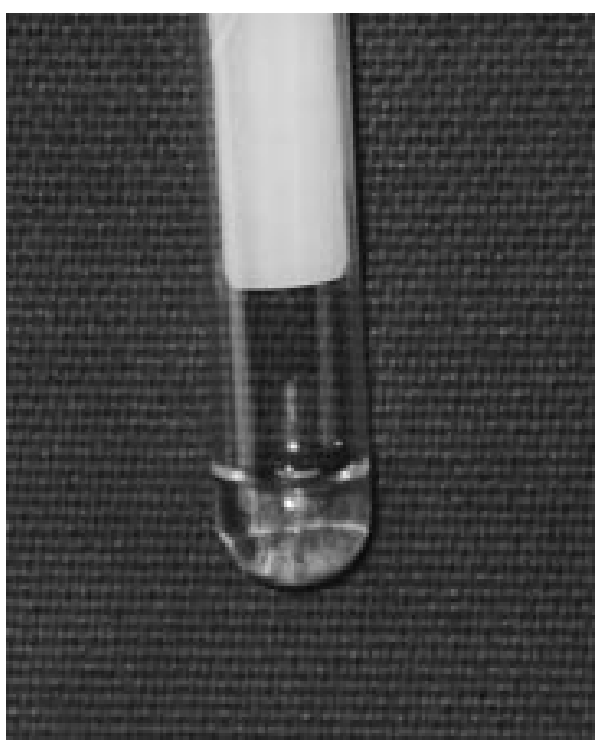

Figure 1 Synovial fluid analysis showing mucin clot formation.

\section{DISCUSSION}

A transient non-inflammatory joint effusion was described for the first time by Woods et al in a patient treated with high dose corticosteroids for the management of renal transplantation, but the characteristics of this effusion were not reported. In other cases of patients treated for renal transplant rejection or lupus nephritis in whom analysis was performed, the synovial fluid was a light yellow or colourless fluid with normal viscosity, low leucocyte count, and lymphocyte or monocyte predominance. $^{23}$ MacFarlane et al studied the relation between corticosteroid treatment and effusion in patients treated for renal transplantation, by joint radiography, bone scan, and synovial biopsy. ${ }^{4}$ Because these examinations were always normal, it was postulated that the effusion might result from steroid induced transudation of fluid across synovial capillary walls. A transient synovial fluid knee effusion with the same characteristics was also noted by Lally in $28.3 \%$ of patients with chronic obstructive pulmonary disease treated with high dose corticosteroids or during withdrawal from such treatment. ${ }^{5}$ 
We agree with these authors that the small volume of synovial fluid, the low leucocyte counts, the rapidity of accumulation, and the transient nature of the effusion support a pathogenic mechanism related to fluid shifts across the synovial vasculature. Although glucocorticoids are known to exert a membrane stabilising effect, our patient's fluid lost its own characteristics (colour, cells, chemical properties) and became similar to plasma as if it had been subjected to increased synovial capillary intravascular pressure. Synovial tissue permeability is markedly affected by increased vascular forces, which alter filtration pressure and synovial fluid production. Bertone et al showed, in an animal study, an increase in trans-synovial fluid flow associated with an increase in arterial and venous pressure. ${ }^{6}$ Raised arterial pressure, which is a side effect of high dose corticosteroid treatment, and low oncotic pressure due to a low protein plasma concentration in a nephrotic patient, can increase the trans-synovial fluid flow at a lower arterial pressure than normal. This rare side effect of high dose corticosteroid treatment should not be forgotten.

\author{
Authors' affiliations \\ F Schiavon, Division of Rheumatology, Via Giustiniani 2, 35142 \\ Padova, Italy \\ Correspondence to Professor F Schiavon; f.schiavon@unipd.it \\ Accepted 8 August 2002
REFERENCES
1 Woods JE, Anderson CF, De Weerd JH, Johnson WJ, Donadio JV, Leary $\mathrm{FJ}$, et al. High-dosage intravenously administered methylprednisolone in renal transplantation: a preliminary report. JAMA 1973;223:896-9.
2 Bennet WM, Strong D. Arthralgia after high-dose steroids. Lancet $1975 ; i: 332$
3 Cathcart ES, Scheinberg MA, Idelson BA, Couser WG. Beneficial effects of methylprednisolone "pulse" therapy in diffuse proliferative lupus nephritis. Lancet 1976;i:163-6.
4 MacFarlane JD, Filo RS, Brandt KD. Joint effusion after kidney transplantation. Arthritis Rheum 1979;22:164-9.
5 Lally EV. High-dose corticosteroid therapy: association with non-inflammatory synovial effusion. Arthritis Rheum 1983;26:1283-7
6 Bertone AL, Hardy J, Simmons EJ, Muir WW 3rd. Vascular and transsynovial forces of the isolated stationary equine joint. Am J Vet Res 1998;59:495-503

\section{Effects of interferon $\alpha$ treatment on the clinical course of refractory Behçet's disease: an open study}

M Çalgüneri, M A Öztürk, i Ertenli, S Kiraz, Ş Apraş, Z Özbalkan

trea nterferon $\alpha$ (IFN $\alpha)$ has recently been introduced in the treatment of uveitis, mucocutaneous lesions, and arthritis of Behçet's disease (BD). ${ }^{1-6}$ To our knowledge, there is currently no clinical trial which has evaluated the efficacy of IFN $\alpha$ treatment in the vascular or neurological involvement in BD. In this open study we evaluated the efficacy, toxicity, and tolerability of IFN $\alpha$ in the management of BD with ocular, articular, vascular, or neurological manifestations which had previously been unsuccessfully treated conventionally.

\section{PATIENTS AND METHODS}

A total of 29 patients (17 men, 12 women; mean age 33.2 months, range 16-51) who were resistant to conventional treatments were treated with systemic IFN $\alpha$. Previous conventional treatments had been colchicine, aspirin, and penicillin plus sulfasalazine for patients with arthritis; or colchicine, aspirin, and penicillin plus steroids and/or immunosuppressive agents, azathioprine, cyclosporin A, or cyclophosphamide for ocular, vascular, and/or neurological involvement. The mean duration of the disease was 8.86 years (range $1-30$ ). Four patients were excluded from the statistical analysis because of the short duration of treatment ( $<4$ months).

Seventeen patients had ocular inflammation. Eleven patients had arthritis. Ten patients had vascular disease (aneurisms in the internal cerebral and ophthalmic arteries; thrombosis of popliteal veins and left anterior descending coronary artery causing myocardial infarction; organised thrombus in superior and inferior caval, iliac, and femoral veins causing intractable ascites; thrombophlebitis; thromboses of internal jugular vein and sigmoid sinus; thrombosis of pulmonary arteries together with intracardiac thrombus in the right ventricle; thrombosis of popliteal vein and ulcerated erythema nodosum; thrombosis of deep veins of the lower extremities only; thromboses of superior vena cava, jugular, and brachiocephalic veins; and thrombosis of sagittal sinus).
Four patients had parenchymal neurological complications which were diagnosed with physical examination and magnetic resonance imaging.

All patients were treated with colchicine $1.5 \mathrm{mg}$ /day orally in three divided doses, aspirin $80 \mathrm{mg} /$ day, and intramuscular benzathine penicillin 1.2 million units every three weeks. Thrombotic occlusions were also treated with anticoagulant agents. Cyclophosphamide was continued together with IFN $\alpha$ in one patient with neurological and vascular disease.

The patients were followed up regularly every 3-6 months. The IFN $\alpha$ dose was 5 million units subcutaneously three times a week, and this was tapered to 3 million units three times a week after 6-9 months as clinical response was achieved. The dose intervals were then gradually increased. The dose of IFN $\alpha$ was increased to 10 million units in one patient because of a lack of response.

Data were evaluated according to the following criteria: complete remission, disappearance of all manifestations during treatment; partial remission, $>50 \%$ decrease in the number, severity, duration, and/or frequency of recurrence of the lesions; stable disease, $<50 \%$ change in the manifestations; and progressive disease, $>50 \%$ deterioration of existing manifestations or/and the development of new ones. ${ }^{7}$

The visual acuity of two patients had deteriorated severely before they were admitted to our clinic. The IFN $\alpha$ treatment prevented new relapses, and, moreover, after the treatment both patients regained a satisfactory visual acuity which was sufficient for the maintenance of daily activities. Another patient had had intractable ascites due to the organised thrombus in the superior and inferior caval, iliac, and femoral veins. Anticoagulation plus IFN $\alpha$ reduced the amount of ascitic fluid without additional vascular event and improved the general clinical condition of the patient. Those three patients were classified as "remission with sequela". 
Table 1 Response rates for the distinct forms of clinical manifestations in our patients with Behçet's disease. Results are shown as No (\%)

\begin{tabular}{|c|c|c|c|c|}
\hline Type of clinical manifestation & $\begin{array}{l}\text { Complete } \\
\text { remission }\end{array}$ & $\begin{array}{l}\text { Remission with } \\
\text { sequela }\end{array}$ & Partial response & $\begin{array}{l}\text { Progressive } \\
\text { disease }\end{array}$ \\
\hline Uveitis & $13 / 17(76)$ & $2 / 17(12)$ & $1 / 17(6)$ & $1 / 17(6)$ \\
\hline Arthritis & $11 / 11(100)$ & & & \\
\hline Vascular disease & $9 / 10(90)$ & $1 / 10(10)$ & & \\
\hline Neurological disease & $4 / 4(100)$ & & & \\
\hline
\end{tabular}

\section{RESULTS}

The mean duration of IFN $\alpha$ treatment was 22.2 months (range 5-72). The overall response rate was 96\% (24/25). Table 1 shows the response rates for the distinct forms of clinical manifestations.

Flu-like symptoms were recorded in eight patients. Serum transaminase levels were reversibly raised in two patients. Although no patient had to discontinue IFN $\alpha$, the dose was reduced to 3 million units three times a week in one patient because of intolerance.

\section{DISCUSSION}

IFN $\alpha$ has previously been given in the treatment of BD with mucocutaneous, articular, and/or ophthalmological manifestations. ${ }^{1-6}$ Zouboulis and Orfanos extensively reviewed 144 patients with BD who were treated with IFNo. ${ }^{7}$ Seventy four per cent $(92 / 124)$ of these patients with mucocutaneous manifestations, 95\% (37/39) with uveitis, and 93\% (51/55) with arthropathy/arthritis showed a partial or complete response. We found similar response rates for uveitis (16/17, $94 \%)$ and arthritis (11/11, 100\%) .

Although the therapeutic potential of IFN $\alpha$ in $\mathrm{BD}$ with vascular or neurological involvement has not been previously investigated, there are some anecdotal reports. In one study treatment with IFN $\alpha$ resulted in complete remission of ocular vasculitis with reperfusion of most of the occluded vessels. ${ }^{2}$ One patient with BD with gastrointestinal vasculitis ${ }^{8}$ and two patients with superficial thrombophlebitis improved after IFN $\alpha$ treatment. ${ }^{45}$ Two patients with neuro-BD were reported to be responsive to treatment with IFN $\alpha .{ }^{19}$ In our study, IFN $\alpha$ produced remission in all patients with neurological or vascular disease (table 1), and, moreover, no recurrence or major toxicity was seen during the long term follow up.

There is no consensus on the dose of IFN $\alpha$ which should be used for the treatment of BD. In most trials the dose ranged between 3 and 9 million units daily or three times a week. ${ }^{1-7}$ The risk of IFN $\alpha$ related retinopathy and splinter haemorrhages is increased at high doses. ${ }^{10}$ Moreover, relatively low doses were found to be as effective as the high IFN $\alpha$ doses, with fewer side effects. ${ }^{4}$ Therefore, we started the treatment with 5 million units three times a week. The duration of IFN $\alpha$ treatment is also controversial. Most studies have used the drug for a 3-6 month course, although shorter and longer treatments have also been reported.$^{1-7}$ Recurrences have been reported in a number of patients when treatment was stopped..$^{1-7}$ Accordingly, we continued the IFN $\alpha$ treatment with dose tapering and later increasing the intervals between doses. Evaluation of response to any treatment including IFN $\alpha$ is complicated and is usually based on the clinical features of BD. Therefore some of the criteria mentioned in the manuscript remain subjective. However, the results of this open study suggest that IFN $\alpha$ may be an effective, safe, and well tolerated therapeutic alternative in $\mathrm{BD}$ where sight or life is threatened. Controlled studies are needed to elucidate its possible role as a first line agent in BD and its optimal therapeutic dosage and duration of treatment.

\section{Authors' affiliations}

M Çalgüneri, M A Öztürk, i Ertenli, S Kiraz, Ş Apraş, Z Özbalkan, Department of Rheumatology Hacettepe University School of Medicine, Ankara, Turkey

Correspondence to: DrM A Öztürk, Ostim mahallesi 89. sokak, AK-84 sitesi, A-2 blok No:8, TR-06170, Yenimahalle, Ankara, Turkey; makifozturk@yahoo.com

Accepted 12 November 2003

\section{REFERENCES}

1 Pivetti-Pezzi P, Accorinti M, Pirraglia MP, Priori R, Valesini G. Interferon alpha for ocular Behçet's disease. Acta Ophthalmol Scand 1997:75:720-2

2 Kötter I, Eckstein AK, Stübiger N, Zierhut M. Treatment of ocular symptoms of Behçet's disease with interferon alpha $2 \mathrm{a}$ : a pilot study. $\mathrm{Br} \mathrm{J}$ Ophthalmol 1998:82:488-94.

3 O'Duffy JD, Calamia K, Cohen S, Goronzy JJ, Herman D, Jorizzo J, et al. Interferon-alpha treatment of Behçet's disease. J Rheumatol 1998;25:1938-44

4 Georgiou S, Monastirli A, Pasmatzi E, Gartaganis S, Goerz G, Tsambaos $D$. Efficacy and safety of systemic recombinant interferon-alpha in Behçet's disease. J Intern Med 1998;243:367-72.

5 Azizlerli G, Sarica R, Kose A, Ovul C, Kavala M, Kayabali M, et al. Interferon alfa-2a in the treatment of Behçet's disease. Dermatology 1996; 192:239-41

6 Hamuryudan V, Moral F, Yurdakul S, Mat C, Tuzun Y, Ozyazgan Y, et al. Systemic interferon alpha $2 \mathrm{~b}$ treatment in Behçet's syndrome. J Rheumatol 1994:21:1098-100.

7 Zouboulis CC, Orfanos CE. Treatment of Adamantiades-Behçet disease with systemic interferon alfa. Arch Dermatol 1998;134:1010-16.

8 Kötter I, Stübiger N, Eckstein AK, Helligenhaus A, Günaydin I, Jacki SH et al. Treatment of ocular Behçet's disease (BD) with recombinant human interferon alpha $2 a(r h I F N-\alpha 2 a)$ : a three center pilot study [abstract]. Arthritis Rheum 1998;41(suppl):S355.

9 Nichols JC, Ince A, Akduman L, Mann ES. Interferon-alpha 2a treatment of neuro-Behçet disease. J Neuroophthalmol 2001;21:109-11.

10 Guyer DR, Tiedeman J, Yannuzzi LA, Slakter JS, Parke D, Kelley J, et al. Interferon-associated retinopathy. Arch Ophthalmol 1993;1 11:350-6. 